\title{
Effects of Partial and Complete Ablation of the Slow Pathway on Fast Pathway Properties in Patients with Atrioventricular Nodal Reentrant Tachycardia
}

\author{
S. ADAM STRICKBERGER, M.D., EMILE DAOUD, M.D., MARK NIEBAUER, M.D., \\ BRIAN D. WILLIAMSON, M.D., K. CHING MAN, D.O., JOHN D. HUMMEL, M.D., \\ and FRED MORADY, M.D.
}

From the Division of Cardiology, Department of Internal Medicine, University of Michigan Medical Center, Ann Arbor, Michigan

\begin{abstract}
Fast Pathway Properties. Introduction: The purpose of this study was to prospectively compare the effects of complete and partial ablation of slow pathway function on the fast pathway effective refractory period (ERP).

Methods and Results: The subjects were 20 patients (mean age $43 \pm 13$ years) with atrioventricular nodal reentrant tachycardia (AVNRT), no structural heart disease, and easily inducible AVNRT. Autonomic blockade was achieved with propranolol $(0.2 \mathrm{mg} / \mathrm{kg})$ and atropine $(0.04 \mathrm{mg} / \mathrm{kg})$. After elimination of AVNRT and during autonomic blockade, the presence of residual slow pathway function was determined by the presence of a single $\mathrm{AV}$ nodal echo and/or dual AV nodal physiology. After autonomic blockade and before ablation, the mean fast pathway ERP was $319 \pm 44 \mathrm{msec}$ and the mean slow pathway ERP was $251 \pm 31$ msec. After slow pathway ablation and during autonomic blockade, 7 patients had residual slow pathway function and 13 did not. Complete loss of slow pathway function was associated with a shortening of the fast pathway ERP from $334 \pm 35 \mathrm{msec}$ to $300 \pm 62 \mathrm{msec}$ ( $P<0.01$ ), while the fast pathway ERP did not change significantly in patients with residual slow pathway function $(291 \pm 29 \mathrm{msec}$ vs $303 \pm 38 \mathrm{msec}$, respectively; $P=0.08)$. A shortening of 30 msec or more in the fast pathway ERP was observed in 11 of 13 patients who did not have residual slow pathway function, compared to 0 of 7 patients with residual slow pathway function $(P<0.001)$.

Conclusion: Shortening of the fast pathway ERP after successful ablation of AVNRT is dependent upon complete loss of slow pathway function. This observation is consistent with electrotonic inhibition of the fast pathway by the slow pathway. ( $\mathrm{J}$ Cardiovasc Electrophysiol, Vol. 5, pp. 645-649, August 1994)
\end{abstract}

autonomic blockade, radiofrequency energy, paroxysmal supraventricular tachycardia

\section{Introduction}

Successful endpoints for elimination of atrioventricular nodal reentrant tachycardia (AVNRT) by radiofrequency catheter ablation of the slow pathway consist of elimination of all slow pathway function ${ }^{1,2}$ or elimination of the induction

Address for correspondence: S. Adam Strickberger, M.D., University of Michigan Medical Center, 1500 East Medical Center Drive, Ann Arbor, MI 48109-0022. Fax: 313-936-7641.

Manuscript received 27 April 1994; Accepted for publication 5 July 1994. of AVNRT with evidence of residual slow pathway function. ${ }^{3,4}$ The fast pathway effective refractory period (ERP) has been observed to shorten paradoxically after slow pathway ablation ${ }^{1,5}$; however, the mechanism of this effect has been unclear. No prior study has compared the effect of complete and partial ablation of slow pathway function on the fast pathway ERP. Therefore, in an attempt to elucidate the mechanism by which the fast pathway ERP shortens after slow pathway ablation, this study prospectively determined the effect of partial and complete slow pathway ablation on the ERP of the fast pathway. 


\section{Methods}

\section{Patient Population}

The subjects consisted of 20 patients with typical AVNRT that was reproducibly inducible without pharmacologic intervention during electrophysiologic testing who underwent radiofrequency ablation of the slow pathway. The 20 patients consisted of 15 women and 5 men with a mean age of $43 \pm 14$ years ( \pm SD). No patient had structural heart disease. The patients had been symptomatic for a mean of $17 \pm 12$ years and had been treated with a mean of $1.9 \pm 1.0$ antiarrhythmic medications before the ablation procedure.

\section{Electrophysiologic Testing}

The investigational protocol was approved by the Committee for Human Research at the University of Michigan and informed consent was obtained from the patients. Electrophysiologic tests were performed in the fasting state after all antiarrhythmic medications had been discontinued for at least 5 half-lives. Three 7-French quadripolar electrode catheters were inserted into a femoral vein and positioned in the high right atrium, across the tricuspid valve to record the His-bundle electrogram, and in the right ventricle. The catheter across the tricuspid valve had a 4-mm distal electrode and a deflectable tip (Mansfield, Watertown, MA, USA) and was also used for ablation. Leads $V_{1}, I$, II, and III and the intracardiac electrograms were displayed on an oscilloscope and recorded on a Mingograf 7 recorder (Siemens-Elema, Solna, Sweden). After the catheters were positioned, 3000 units of heparin was administered intravenously. Pacing was performed with a programmable stimulator (Bloom Associates, Reading, PA, USA).

The diagnostic portion of the electrophysiologic test was directed at determining the presence of dual AV nodal physiology, measuring the conduction properties and refractory periods of the fast and slow AV nodal pathways, and inducing and determining that the mechanism of the paroxysmal supraventricular tachycardia was typical AVNRT. ${ }^{6}$ Incremental pacing and programmed stimulation were performed in the right atrium and right ventricle to define anterograde and retrograde AV nodal conduction and refractoriness and to confirm that typical AVNRT could be reproducibly provoked.

\section{Study Protocol}

In order to eliminate the possible confounding effects of changes in sympathetic or vagal tone, the study protocol was performed during autonomic blockade. Autonomic blockade was achieved with intravenous atropine $(0.04 \mathrm{mg} / \mathrm{kg})$ and intravenous propranolol $(0.2 \mathrm{mg} / \mathrm{kg}) .^{7}$ These drugs were administered simultaneously over 5 minutes. Five minutes later, atrial and ventricular incremental and programmed stimulation were performed. After successful elimination of inducible AVNRT with radiofrequency energy, propranolol and atropine were administered in doses sufficient to achieve a sinus cycle length within $20 \mathrm{msec}$ of the preablation sinus cycle length, and electrophysiologic testing was repeated.

The mean initial doses of atropine and propranolol were $2.9 \pm 0.2$ and $14.3 \pm 3.4 \mathrm{mg}$, respectively. The mean ablation procedure duration was $37 \pm 25$ minutes. After the ablation procedure, there were ten patients in whom the sinus cycle length was within $20 \mathrm{msec}$ of the preablation sinus cycle length, and, therefore, administration of additional atropine or propranolol was not necessary. Among the other ten patients, a mean of $1.2 \pm 0.7$ $\mathrm{mg}$ of atropine and $5.0 \pm 2.2 \mathrm{mg}$ of propranolol were administered before retesting.

AV nodal echo beats were defined as echo beats that had a concentric atrial activation sequence, occurred in association with prolongation of the AH interval, were reproducible, were simultaneous with the QRS complex, and which had a fixed ventriculoatrial relationship.

After successful ablation of AVNRT, the presence or absence of residual slow pathway function was noted. The criteria for residual slow pathway function consisted of dual AV nodal physiology and/or AV nodal echo beats after elimination of inducible AVNRT.

\section{Catheter Ablation Protocol}

Radiofrequency energy was delivered by a generator (EP Technologies, Inc., Sunnyvale, CA, USA) that supplied a continuous, unmodulated sine wave output at a frequency of $500 \mathrm{kHz}$. Suitable target sites for slow pathway ablation were identified during sinus rhythm. Mapping was performed in the low posterior right atrium, in the region of the coronary sinus os. Target sites were identified by an A:V electrogram ratio $<0.5$ and by the presence of a possible slow pathway potential or a multicomponent atrial electrogram. ${ }^{3,8,9}$ After a target site was identified, radiofrequency 
current was applied at 30 watts for 10 to 30 seconds. The inducibility of AVNRT was assessed after each application of radiofrequency energy. In each patient, the inducibility of AVNRT was successfully eliminated.

\section{Statistical Analysis}

Continuous variables are expressed as mean \pm 1. SD and were compared using the Student's $t$ test for paired or unpaired variables. Nominal variables were compared by Chi-square analysis. $\mathrm{P}$ values $<0.05$ were considered statistically significant.

\section{Results}

After elimination of inducible AVNRT, 7 patients had evidence of residual slow pathway function and 13 patients did not (Table 1). Among the seven patients in whom there was residual slow pathway function, the mean slow pathway ERP was $243 \pm$ $33 \mathrm{msec}$ before ablation, and $254 \pm 36 \mathrm{msec}$ after ablation $(P=0.10)$. In the entire cohort of 20 patients, the fast pathway ERP was $319 \pm 44 \mathrm{msec}$ before ablation and $301 \pm 54 \mathrm{msec}$ after ablation $(\mathrm{P}=0.05)$.

In the 13 patients without residual slow pathway function, the fast pathway ERP shortened from $334 \pm 45 \mathrm{msec}$ before ablation to $300 \pm 62$ msec after ablation $(P<0.01)$. In contrast, the fast pathway ERP in patients who had residual slow pathway function after ablation did not change significantly from before ablation (303 \pm 38 vs $291 \pm 29 \mathrm{msec} ; \mathrm{P}=0.08$ ). Among the 13 patients without residual slow pathway function, 11 patients demonstrated a $30 \mathrm{msec}$ or more shortening of the fast pathway ERP, compared to 0 of the 7 patients with residual slow pathway function $(\mathrm{P}<0.001)$

\section{Discussion}

\section{Main Findings}

The results of this study demonstrate that shortening of the fast pathway ERP after slow pathway ablation is observed only when there is complete ablation of slow pathway function. With partial ablation of slow pathway function, as manifest by persistent AV nodal echoes or dual AV nodal physiology, shortening of the fast pathway ERP is not observed. These data suggest that there may be electrotonic inhibition of the fast pathway by the slow pathway, and that loss of this electrotonic effect occurs only when slow pathway function is completely eliminated.

TABLE 1

Electrophysiologic Characteristics During Autonomic Blockade

\begin{tabular}{|c|c|c|c|c|c|c|c|c|c|}
\hline \multirow[b]{2}{*}{ Pt. No. } & \multicolumn{2}{|c|}{ SCL (msec) } & \multicolumn{2}{|c|}{ FP ERP (msec) } & \multicolumn{2}{|c|}{ SP ERP (msec) } & \multicolumn{2}{|c|}{ Dual AVN } & \multirow{2}{*}{$\begin{array}{l}\text { Post } \\
\text { Echo }\end{array}$} \\
\hline & Pre & Post & Pre & Post & Pre & Post & Pre & $\overline{\text { Post }}$ & \\
\hline 1 & 730 & 740 & 380 & 350 & 300 & - & Yes & No & No \\
\hline 2 & 480 & 470 & 270 & 270 & 200 & 200 & Yes & Yes & Yes \\
\hline 3 & 550 & 550 & 310 & 330 & 240 & 250 & Yes & Yes & Yes \\
\hline 4 & 800 & 800 & 350 & 420 & 230 & - & Yes & No & No \\
\hline 5 & 650 & 650 & 380 & 320 & 260 & - & Yes & No & No \\
\hline 6 & 490 & 480 & 240 & 240 & 210 & 200 & Yes & Yes & Yes \\
\hline 7 & 580 & 580 & 260 & 220 & 220 & - & Yes & No & No \\
\hline 8 & 760 & 780 & 280 & 290 & 250 & 250 & Yes & Yes & Yes \\
\hline 9 & 520 & 530 & 310 & 320 & 250 & 270 & Yes & Yes & Yes \\
\hline 10 & 480 & 470 & 270 & 220 & 260 & - & Yes & No & No \\
\hline 11 & 690 & 710 & 320 & 230 & 250 & - & Yes & No & No \\
\hline 12 & 750 & 750 & 410 & 370 & 200 & - & Yes & No & No \\
\hline 13 & 740 & 730 & 340 & 310 & 270 & - & Yes & No & No \\
\hline 14 & 750 & 740 & 310 & 270 & - & - & No & No & No \\
\hline 15 & 680 & 700 & 310 & 350 & 300 & 330 & Yes & Yes & Yes \\
\hline 16 & 950 & 950 & 330 & 270 & 270 & - & Yes & No & No \\
\hline 17 & 460 & 470 & 290 & 250 & 230 & - & Yes & No & No \\
\hline 18 & 630 & 620 & 330 & 340 & 300 & - & Yes & No & No \\
\hline 19 & 520 & 520 & 320 & 320 & 250 & 280 & Yes & Yes & Yes \\
\hline 20 & 690 & 710 & 370 & 330 & 280 & - & Yes & No & No \\
\hline Mean $\pm S D$ & $645 \pm 132$ & $648 \pm 133$ & $319 \pm 44$ & $301 \pm 54$ & $251 \pm 31$ & $254 \pm 46$ & & & \\
\hline
\end{tabular}

Dual AVN = dual atrioventricular nodal physiology; Echo = AVN echo beat; FP $=$ fast pathway; Pre $=$ preablation; Post $=$ postablation; $\mathrm{SCL}=$ sinus cycle length; $\mathrm{SP}=$ slow pathway. 


\section{Comparison to Previous Studies}

Successful ablation of AVNRT in this study was defined as the inability to induce AVNRT, even if there was evidence of residual slow pathway function. $4,9,10$ In a previous study evaluating the effect of slow pathway function on the fast pathway ERP, the endpoint for ablation was complete elimination of slow pathway function. ${ }^{2}$ This prior study reported a shortening of the fast pathway ERP after complete ablation of slow pathway function. ${ }^{2}$ However, because the endpoint for ablation in that study was the elimination of all slow pathway function, the effect of incomplete ablation of the slow pathway could not be determined. The present study is the first to demonstrate that shortening of the fast pathway ERP after elimination of inducible AVNRT is observed when there is complete ablation of slow pathway function, but not when residual slow pathway function persists.

\section{Electrotonus and Other Possible Mechanisms}

Electrotonus is a phenomenon in which there is passive current flow due to voltage gradients between cells. This passive current flow may lengthen the refractory period of adjacent cells by causing subthreshold depolarizations." The passive cable properties of the tissue determine the characteristics of the response. After successful elimination of AVNRT utilizing the slow pathway approach, electrotonic inhibition of the fast pathway by the slow pathway could exist only if there was residual slow pathway function. In this circumstance, as observed in the present study, the fast pathway ERP would not be expected to shorten. With complete ablation of slow pathway function, electrotonic inhibition of the fast pathway by the slow pathway would be eliminated, as observed in this study.

Shortening of the fast pathway ERP after slow pathway ablation has been proposed to be secondary to alterations in autonomic tone or loss of parasympathetic innervation. ${ }^{1}$ Because the data in the present study were obtained in the setting of autonomic blockade, shortening of the fast pathway ERP cannot be explained by changes in sympathetic or parasympathetic tone.

Finally, it is possible that with complete loss of all slow pathway function after the ablation procedure, there is some destruction of the most proximal portion of the compact AV node, which does not occur with incomplete ablation of slow path- way function. A smaller, compact AV node would provide a smaller "sink," which could subsequently contribute to shorter refractory periods. This hypothesis is unlikely, as most effective applications for elimination of slow pathway function are in the $P_{1}$ to $\mathrm{P}_{2}$ region, ${ }^{9}$ and, hence, it would be unlikely that any portion of the compact $\mathrm{AV}$ node would be destroyed.

\section{Conclusion}

Shortening of the fast pathway ERP after successful elimination of AVNRT is only observed after complete ablation of slow pathway function and not after partial ablation of slow pathway function. This observation is consistent with the hypothesis that there is electrotonic inhibition of the fast pathway by the slow pathway and that loss of this electrotonic effect requires complete elimination of slow pathway function.

Acknowledgment: The authors gratefully acknowledge the excellent secretarial support of Mrs. Betty Plunkett.

\section{References}

1. Kay GN, Epstein AE, Dailey SM, et al: Selective radiofrequency ablation of the slow pathway for the treatment of atrioventricular nodal reentrant tachycardia: Evidence for involvement of perinodal myocardium within the reentrant circuit. Circulation 1992;85:1675-1688.

2. Natale A, Klein G, Yee R, et al: Shortening of fast pathway refractoriness after slow pathway ablation: Effects of autonomic blockade. Circulation 1994;89:1103-1108.

3. Jackman WM, Beckman KJ, McClelland JH, et al: Treatment of supraventricular tachycardia due to atrioventricular nodal reentry, by radiofrequency catheter ablation of slow-pathway conduction. N Engl J Med 1992;327:313-318.

4. Lindsay BD, Chung MK, Gamache MC, et al: Therapeutic end points for the treatment of atrioventricular node reentrant tachycardia by catheter-guided radiofrequency current. J Am Coll Cardiol 1993;22:733-740.

5. Wathen M, Natale A, Wolfe K, et al: An anatomically guided approach to atrioventricular node slow pathway ablation. Am J Cardiol 1992;70:886-889.

6. Calkins H, Sousa J, El-Atassi R, et al: Diagnosis and cure of the Wolff-Parkinson-White syndrome or paroxysmal supraventricular tachycardia during a single electrophysiologic test. N Engl J Med 1991;324:16121618.

7. Jose AD, Taylor RR: Autonomic blockade by propra- 
nolol and atropine to study intrinsic myocardial function in man. J Clin Invest 1969;48:2019-2031.

8. Haissaguerre M, Gaita F, Fischer B, et al: Elimination of atrioventricular nodal reentrant tachycardia using discrete slow potentials to guide application of radiofrequency energy. Circulation 1992;85:21622175.

9. Kalbfleisch SJ, Strickberger SA, Williamson B, et al: Randomized comparison of anatomic and electrogram mapping approaches to ablation of the slow pathway of atrioventricular node reentrant tachycardia. J Am Coll Cardiol 1994;23:716-723.

10. Shen WK, Hammill SC, Packer DL: Fast pathway properties before and after slow pathway ablation in patients with AV node reentrant tachycardia. J Am Coll Cardiol 1994:1A-484A.

11. Antzelevitch $C$ : Electrotonus and reflection. In Rosen MR, Janse MJ, Wit AL, eds: Cardiac Electrophysiology: A Textbook. Futura Publishing Company, Inc., Mount Kisco, NY, 1990, pp. 491-516. 
This document is a scanned copy of a printed document. No warranty is given about the accuracy of the copy. Users should refer to the original published version of the material. 